\title{
CONE-97/130--1 \\ INELLON-97-10261 INEL/CON-97-00261 \\ Condensation Enhancement on a Pool Surface Caused by a Submerged Liquid Jet
}

\author{
Rex W. Shumway
}

Lockheed Martin Idaho Technologies Company

Idaho National Engineering and Environmental Laboratory

Idaho Falls, Idaho

Work Supported by the US-Nuclear Regulatory Commission under DOE Idalf QPe
Office Contract DE-AC07-94ID13223

\section{ABSTRACT}

One advanced nuclear reactor design has a residual heat removal (RHR) pipe connected to the bottom of a steam generator outlet plenum. The water in the plenum can become thermally stratified during postulated loss of coolant accidents. Cold water injected through the RHR pipe has the potential effect of increasing the steam condensation on the pool surface due to the stirring action of the jet. The amount of increase depends on a number of factors, including the jet velocity and the pool height above the jet injection point. Prediction of steam condensation rates, before and after the jet breaks the pool surface, is the topic of this paper. Data and correlations exist for pre surface breakthrough and a method has been developed for post breakthrough. The models have been incorporated into the reactor safety analysis computer software known as RELAP5. Comparisons of predictions against data are presented.

\section{NOMENCLATURE}
$\mathrm{A}=$ area
$\mathrm{C}_{\mathrm{p}} \quad=$ specific heat at constant pressure
D = hydraulic diameter, tank diameter
$\mathrm{d} \quad=$ jet diameter
g = gravitational acceleration
$\mathrm{G}$ = condensate mass flux across the interface
Or $=$ Grashof number $=\beta g \Delta T \rho^{2} D^{3} / \mu^{2}$

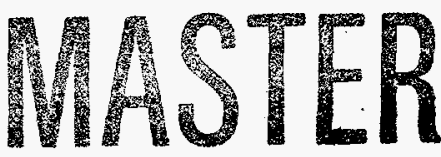
$\mathrm{h}_{\mathrm{if}} \quad=$ liquid interfacial heat transfer coefficient $=\mathrm{q}^{\prime \prime} /\left(\mathrm{T}_{\mathrm{s}}-\mathrm{T}_{\mathrm{f}}\right)$ 


$$
\begin{array}{ll}
\mathrm{h}_{\mathrm{fg}} & =\text { enthalpy difference between vapor and liquid at saturation } \\
\mathrm{Ja} & =\text { Jakob Number, } \mathrm{C}_{\mathrm{pf}}\left(\mathrm{T}_{\mathrm{s}}-\mathrm{T}_{\mathrm{f}}\right) / \mathrm{h}_{\mathrm{fg}} \\
\mathrm{k} & =\text { conductivity } \\
\mathrm{l} & =\text { length of liquid jet } \\
\mathrm{m} & =\text { steam mass flow rate } \\
\mathrm{Nu} & =\text { Nusselt number } \mathrm{h}_{\mathrm{if}} \mathrm{D} / \mathrm{k} \\
\mathrm{Pr} & =\text { Prandtl number }=\mu \mathrm{C}_{\mathrm{p}} / \mathrm{k}, \\
\mathrm{q} & =\text { surface thermal energy transfer rate } \\
\mathrm{q} & =\text { surface heat flux } \\
\mathrm{Q} & =\text { liquid volumetric flow } \mathrm{rate} \text { through tank } \\
\mathrm{Ra} & =\text { Rayleigh number }=\mathrm{GrPr} \\
\mathrm{Ri} & =\text { Richardson number }=\left(\frac{\mathrm{Gr}}{\mathrm{Re}}\right) \\
\mathrm{Re} & =\text { Reynolds number }=\rho \mathrm{VT} / \mu \\
\mathrm{St} & =\text { Stanton number }=\mathrm{Nu} /(\operatorname{RePr})=\mathrm{h}_{\mathrm{if}} /\left(\rho \mathrm{C}_{\mathrm{p}} \mathrm{v}\right) \\
\mathrm{T} & =\text { temperature } \\
\mathrm{v} & =\text { velocity } \\
\mathrm{R} & =\text { water height above the jet injection point } \\
\mathrm{R} & \quad
\end{array}
$$

\section{Subscripts}

$$
\begin{array}{ll}
\mathrm{b} & =\text { bulk property or surface } \\
\mathrm{f} & =\text { liquid property } \\
\mathrm{j} & =\text { jet } \\
\mathrm{s} & =\text { saturation property }
\end{array}
$$




\section{DISCLAIMER}

This report was prepared as an account of work sponsored by an agency of the United States Government. Neither the United States Government nor any agency thereof, nor any of their employees, make any warranty, express or implied, or assumes any legal liability or responsibility for the accuracy, completeness, or usefulness of any information, apparatus, product, or process disclosed, or represents that its use would not infringe privately owned rights. Reference herein to any specific commercial product, process, or service by trade name, trademark, manufacturer, or otherwise does not necessarily constitute or imply its endorsement, recommendation, or favoring by the United States Government or any agency thereof. The views and opinions of authors expressed herein do not necessarily state or reflect those of the United States Government or any agency thereof. 


\section{DISCLAMVER}

Portions of this docoment may be illegible in electronic iroge products. Irogges are produced from the best arailable original docemenest 


\section{Greek Symbols}

$\begin{array}{ll}\beta & =\text { coefficient of thermal expansion or equation constant } \\ \Delta \mathrm{T} & =\mathrm{T}_{\mathrm{s}}-\mathrm{T}_{\mathrm{f}} \\ \Lambda & =\text { turbulence wavelength } \\ \rho & =\text { density } \\ \Delta \rho & =\text { density of liquid minus density of vapor } \\ \sigma \quad & =\text { surface tension } \\ \mu & =\text { viscosity }\end{array}$

\section{INTRODUCTION}

Condensation of steam on the surface of a liquid pool increases when stirred from below by a fluid jet. Condensation increases even more if the jet breaks through the pool surface. Figure 1 illustrates a tank with a steam source, a subcooled water inlet and a liquid drain. This situation occurs in some advanced reactor designs where the tank is the steam generator outlet plenum, the steam source is the steam generator tubes, the water inlet is a residual heat removal system return line and the outlet is the pump suction pipe. Predicting the condensation rate for this situation is the subject of this paper.

The rate of steam-water interfacial heat transfer depends on several factors, including steam pressure and liquid subcooling. If the jet is not strong enough to break the surface, turbulence transport near the pool surface caused by the jet is a dominant factor. Surface turbulence causes a buoyancy-induced insulating layer of condensate to disperse. The degree of turbulence (or surface renewal) depends on the jet velocity, the distance to the pool surface, and the pool and inlet pipe diameters. At higher jet velocities or lower pool levels the jet will break into the steam space and increase the condensation rate.

A survey of analytical and experimental work on this problem is addressed below. The goal of the study was to find analytical methods to use in the reactor safety thermal-hydraulic analysis code (computer software) known as RELAP5 ${ }^{1}$. 


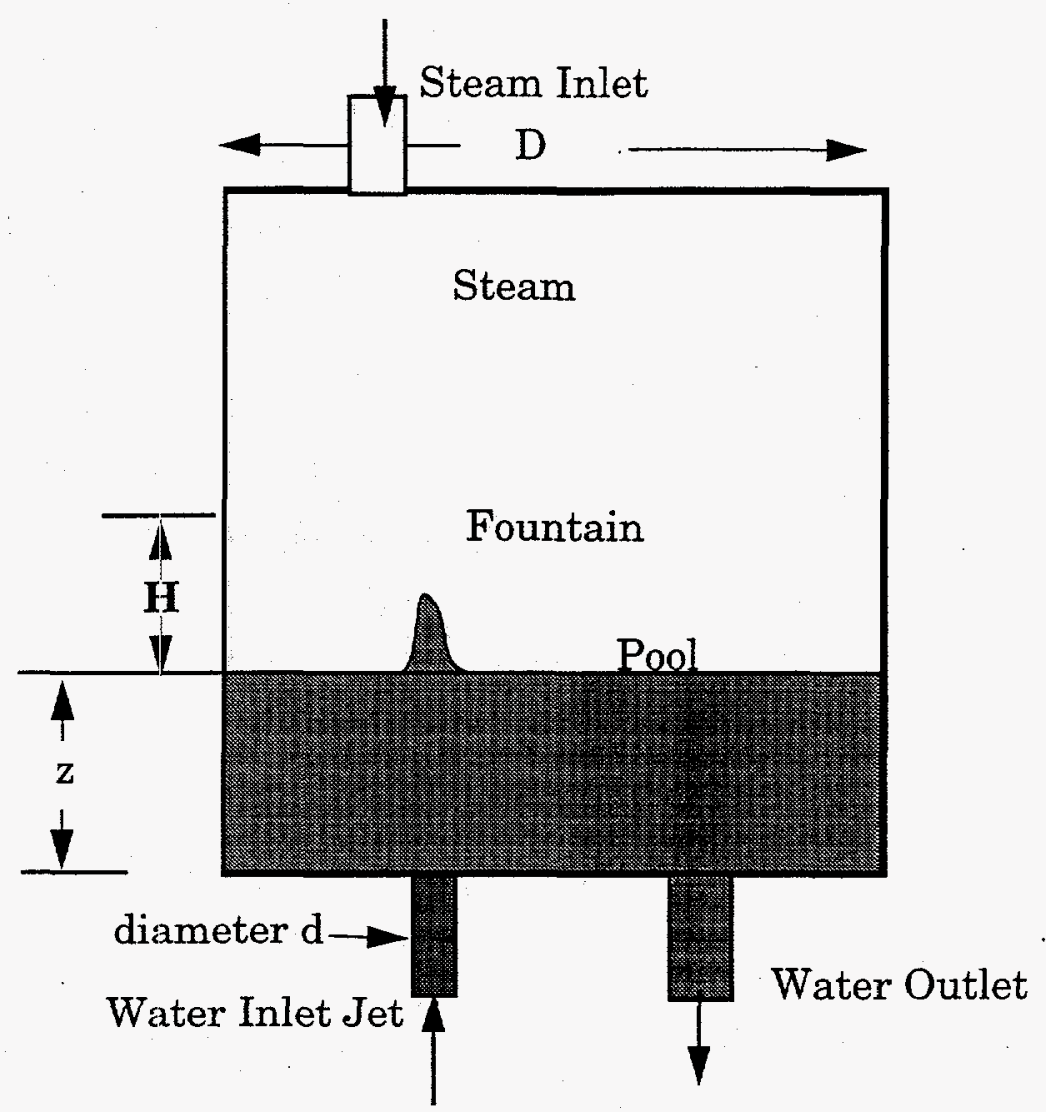

Figure 1. Steam condensation in a tank with surface breakup.

\section{RELAP5 STRATIFIED HEAT TRANSFER}

RELAP5/MOD3 does not consider condensation enhancement on a pool surface caused by a submerged jet. When the flow is stratified, RELAP5 uses a McAdams natural convection correlation to model the heat transfer between the bulk liquid and a saturated interface. This model relates the Nusselt number to the Rayleigh number. The correlation for Nusselt number in terms of Rayleigh number was developed for a cold plate with warm fluid above the plate:

$$
\mathrm{Nu}=0.27 \mathrm{Ra}^{0.25}
$$

The actual heat transfer rate in the plenum should be higher than the natural convection value because of liquid stirring caused by water injection. The purpose of this study is to find more realistic values of interfacial heat transfer. 


\section{EXPERIMENTS AND ANALYSIS}

Several data sources developed for space-based cryogenic storage tanks are available. Although the aspect ratio of some of the hardware tested does not match reactor conditions, ideas about how to predict test results may be useful. Fluids used in the experiments were water and steam at low pressure with no noncondensables present.

The experiments, analysis and correlations will first be presented followed by range of parameters, such as pressure and subcooling and predictions of the heat transfer data. The contributions are presented in chronological order.

\subsection{Theofanous Analysis (1979)}

Theofanous ${ }^{2}$ presented a paper in 1979 which included a correlation to predict condensation on a turbulent liquid jet. Theofanous presented jet condensation models from ten sources and recommended a Stanton number in terms of the jet diameter and length:

$$
\text { St }=0.02\left(\frac{d}{1}\right)^{0.5}
$$

\subsection{Thomas Experiment (1979)}

Thomas ${ }^{3}$ obtained experimental condensation data at pressures near ambient. He used an apparatus similar to the one shown in Figure 1 except that steam was inject in the side and could escape at the top. Liquid was drained at a rate needed to hold the liquid level constant. The steady state liquid level was varied from test to test over a range of $30 \%$ greater than the tank diameter to about one third of the diameter $(1.3 \geq(\mathrm{z} / \mathrm{D}) \geq 0.317)$.

Condensation rate measurements were made at six water levels, with either two or three nozzle diameters. The inlet flow rate was varied to yield nozzle 
Reynolds numbers in the range from about 15,000 to 90,000 . Table 1 gives the geometrical parameters for the fifteen settings used.

Table 1 Thomas Experiment Geometrical Parameters.

\begin{tabular}{|c|c|c|c|c|c|}
\hline $\begin{array}{c}\text { Vessel } \\
\text { Diameter } \\
\mathbf{D}(\mathbf{m})\end{array}$ & $\begin{array}{c}\text { Level } \\
\text { height } \\
\text { above } \\
\text { nozzle, } \mathbf{z} \\
(\mathbf{m})\end{array}$ & $\begin{array}{c}\text { Nozzle } \\
\text { Diameter } \\
\mathbf{d}(\mathbf{m})\end{array}$ & $\mathbf{z} / \mathbf{D}$ & $\mathbf{D} / \mathbf{d}$ & $\mathbf{z} / \mathbf{d}$ \\
\hline \hline 0.3 & 0.39 & 0.00318 & 1.3 & 94.34 & 122.64 \\
\hline 0.3 & 0.39 & 0.00635 & 1.3 & 47.24 & 61.41 \\
\hline 0.3 & 0.39 & 0.0127 & 1.3 & 23.63 & 30.71 \\
\hline 0.3 & 0.34 & 0.00318 & 1.13 & 94.34 & 106.92 \\
\hline 0.3 & 0.34 & 0.00635 & 1.13 & 47.24 & 53.54 \\
\hline 0.3 & 0.29 & 0.00318 & 0.966 & 94.34 & 91.19 \\
\hline 0.3 & 0.29 & 0.00635 & 0.966 & 47.24 & 45.67 \\
\hline 0.3 & 0.29 & 0.0127 & 0.966 & 23.63 & 22.83 \\
\hline 0.3 & 0.22 & 0.00318 & 0.733 & 94.34 & 69.18 \\
\hline 0.3 & 0.22 & 0.00635 & 0.733 & 47.24 & 36.65 \\
\hline 0.3 & 0.15 & 0.00318 & 0.5 & 94.34 & 47.17 \\
\hline 0.3 & 0.15 & 0.00635 & 0.5 & 47.24 & 23.62 \\
\hline 0.3 & 0.15 & 0.0127 & 0.5 & 23.63 & 11.81 \\
\hline 0.3 & 0.095 & 0.00318 & 0.317 & 94.34 & 29.87 \\
\hline 0.3 & 0.095 & 0.00635 & 0.317 & 47.24 & 14.96 \\
\hline & & & & & \\
\hline
\end{tabular}

Thomas also ran an experiment (in a $1.2 \times 1.2 \times 1.8 \mathrm{~m}$ tank) to evaluate the Kutateladze number at which 'surface breakup' occurred. Surface breakup is defined as the point at which the surface is so disturbed by the liquid jet that gas entrainment occurs. Thomas found that the critical Kutateladze number was:

$$
\frac{\rho_{\mathrm{f}} \mathrm{v}_{\mathrm{j}}^{2}}{(\Delta \rho \mathrm{g} \sigma)^{0.5}}=\left(0.46 \frac{\mathrm{z}}{\mathrm{d}}\right)^{2}
$$

Some of his data were taken above the critical value. Surface heat transfer varied almost linearly with the jet Reynolds number below the critical value. All the data points taken at the lowest water level had a Kutateladze number above the critical 
value. The slope of heat transfer coefficient versus Reynolds number was proportional to Reynolds number to the 1.74 power.

\subsection{Sonin, Shimko and Chun Experiment (1986)}

Sonin, Shimko and Chun ${ }^{5}$ state that: "Transport into a liquid surface is intimately tied to the turbulence structure very near the interface." They ran an experiment to obtain data on the turbulence intensity in the liquid and developed a correlation to predict surface heat transfer. All the condensation measurements were made with a water level between 3.1 and 4.2 tank diameters above the nozzle, at a pressure of about 1 bar, and a liquid subcooling between 54 and $70 \mathrm{~K}$. Table 2 shows geometrical data.

Table 2 Sonin, Shimko and Chun Experiment Geometrical Parameters .

\begin{tabular}{|c|c|c|c|c|}
\hline $\begin{array}{c}\text { Vessel Diameter } \\
\mathbf{D}(\mathbf{m})\end{array}$ & $\begin{array}{c}\text { Nozzle Diameter } \\
\mathbf{d}(\mathbf{m})\end{array}$ & $\mathbf{D} / \mathbf{d}$ & $\mathbf{z} / \mathbf{D}$ & $\mathbf{z} / \mathbf{d}$ \\
\hline \hline 0.153 & 0.0064 & 24 & $3.17-4.17$ & $76-100$ \\
\hline 0.038 & 0.0016 & 24 & $3.15-4.20$ & $76-101$ \\
\hline
\end{tabular}

The experimenters used water seeded with polystyrene spheres and a video camera operating at $120 \mathrm{frames} / \mathrm{s}$ to show that the average liquid side turbulence intensity in the 'far field' $(z / D>3)$ is approximately:

$$
\mathrm{v}_{\mathrm{b}}=\Phi(\mathrm{Re})\left(\frac{\mathrm{Q}}{\mathrm{Dd}}\right) \mathrm{e}^{-1.2 \frac{\mathrm{Z}}{\mathrm{D}}}
$$

where

$$
\begin{aligned}
& v_{b} \quad=\text { rms value of turbulent velocity at the surface, } \\
& \operatorname{Re} \quad=\text { system Reynolds number }=\left(\rho_{\mathrm{f}} \mathrm{Q} / \mathrm{Dd}\right)\left(\mathrm{D} / \mu_{\mathrm{f}}\right),
\end{aligned}
$$

$\Phi(\mathrm{Re})=21.8$ fits the data above a Reynolds number of 25,000 . Below this Reynolds number the coefficient becomes larger as shown in Figure 4 of Reference 5. $^{\mathrm{a}}$ The thermal diffusion layer thickness at the water surface was estimated to be of the order of $0.1 \mathrm{~mm}$.

a. Reference 6 says $\Phi(R e)=24.5$ if $\operatorname{Re}<15,000$, and $\Phi(R e)=21.8$ if $\operatorname{Re}>30,000$. 
Turbulence measurements illustrated, as the surface was approached from below, that the vertical turbulence decreased and the horizontal turbulence increased.

Their prediction of the surface heat transfer rate is in terms of a Stanton number:

$$
\text { St }=0.0098
$$

where the Stanton number is based on saturation properties

$$
\text { St } \quad=h_{i f} /\left(\rho_{s} C_{p s} v_{b}\right) \text {, }
$$

The authors claim Equation 5 is valid for: $\mathrm{Pr}_{\mathrm{s}}=1.76, \Delta \mathrm{T} / \mathrm{T}_{\mathrm{s}}<0.21, \mathrm{Ja}<0.13, \mathrm{Re}_{\mathrm{s}}=$ $4000<\rho_{\mathrm{s}} \mathrm{v}_{\mathrm{b}} \mathrm{D} / \mu_{\mathrm{s}}>72,000$.

Note that Equation 5 is independent of bulk properties. The authors show a plot of the liquid side interfacial heat transfer coefficient versus liquid subcooling that is flat, even though the bulk Prandtl varies from about 2 to 6 . They believe the surface (saturation) molecular transport properties should control the turbulence at the surface.

\subsection{Brown, Khoo and Sonin Experiment (1990)}

Brown, Khoo and Sonin 8 extended the work of Sonin, Shimko and Chun. All the condensation measurements were made with a water level 3.67 diameters above the nozzle. Table 3 shows geometrical data.

Table 3 Brown, Khoo and Sonin Experiment Geometrical Parameters.

\begin{tabular}{|c|c|c|c|c|c|}
\hline $\begin{array}{c}\text { Vessel } \\
\text { Diameter } \\
\mathbf{D}(\mathbf{m})\end{array}$ & $\begin{array}{c}\text { Level } \\
\text { height } \\
\text { above } \\
\text { nozzle, } \mathbf{z} \\
(\mathbf{m})\end{array}$ & $\begin{array}{c}\text { Nozzle } \\
\text { Diameter } \\
\mathbf{d}(\mathbf{m})\end{array}$ & $\mathbf{z} / \mathbf{D}$ & $\mathbf{D} / \mathbf{d}$ & $\mathbf{z} / \mathbf{d}$ \\
\hline \hline 0.102 & 0.374 & 0.0042 & 3.67 & 24 & 88.1 \\
\hline 0.038 & 0.139 & 0.0016 & 3.67 & 24 & 88.1 \\
\hline
\end{tabular}

Measurements were taken at pressures of 0.313 and $0.113 \mathrm{MPa}$ at bulk water temperatures of $310,330,344,355$ and $391 \mathrm{~K}$ and many water inlet velocities. 
The experimenters used a laser Doppler velocimeter as well as a video camera to study turbulence. They agreed that the average liquid side turbulence intensity was:

$$
\mathrm{v}_{\mathrm{b}}=21.1\left(\frac{\mathrm{Q}}{\mathrm{Dd}}\right) \mathrm{e}^{-1.2 \frac{\mathrm{z}}{\mathrm{D}}}
$$

but found that heat transfer was a function of the Prandtl number at low Richardson numbers. Their prediction of the surface heat transfer rates comes from the Stanton number:

$$
S t=S t_{o}(1-J a / 2)
$$

where

$$
\begin{aligned}
& \mathrm{St}_{\mathrm{o}} \quad=0.0198 / \mathrm{Pr}_{\mathrm{f}}^{0.33} \text {, for Ri near zero } \\
& \mathrm{St}_{\mathrm{o}} \quad=0.136-0.00081 \mathrm{Ri} \text {, for } 3.5<\mathrm{Ri}<15
\end{aligned}
$$

The Richardson number, Grashof number, and Reynolds number are defined with the surface turbulence macroscale wavelength, $\Lambda$, as the relevant distance.

$$
\begin{aligned}
& \text { Ri } \quad=\text { Richardson Number }=\beta_{\mathrm{f}} \mathrm{g}\left(\mathrm{T}_{\mathrm{s}}-\mathrm{T}_{\mathrm{f}}\right) \Lambda / \mathrm{v}_{\mathrm{b}}{ }^{2}=\left(\frac{\mathrm{Gr}}{\mathrm{Re}^{2}}\right) \\
& \mathrm{Gr} \quad=\text { Grashof number }=\beta_{\mathrm{b}} \mathrm{g} \Delta \mathrm{T}_{\mathrm{b}}{ }^{2} \Lambda^{3} / \mu_{\mathrm{b}}^{2} \\
& \operatorname{Re} \quad=\text { Reynolds number }=\rho_{\mathrm{f}} \mathrm{v}_{\mathrm{b}} \Lambda / \mu_{\mathrm{f}}
\end{aligned}
$$

The turbulence macroscale is an integral of the near-surface velocity fluctuation over time and the authors believe it to be independent of elevation above $z / D=3$. The liquid jet spreads over the entire pipe cross section at about $z / D=3$. Above this height the turbulence macroscale is independent of the Reynolds number, isotropic in direction (at least below the interfacial layer) and is only dependent on the system diameter; i. e.: 
The authors believe Equation 7 is valid under the following conditions; $\mathrm{Ri}<15$, $1<\operatorname{Pr}_{\mathrm{f}}<6,1<\operatorname{Pr}_{\mathrm{s}}<2, \mathrm{Ja}<0.2$, and $350<\operatorname{Re}<11000$.

\subsection{Brown, Helmick and Sonin Experiment (1989)}

Brown, Helmick and Sonin" ran experiments in a geometry similar to that used by Brown, Khoo and Sonin ${ }^{a}$ but took data at lower water levels.

These experimenters suggest a restriction on correlations such as Equation 5 (Stanton number $=$ constant). Brown, Helmick and Sonin ${ }^{7}$ argue that:

"Equation 5 applies only at small Richardson numbers, where gravitational effects are negligible. Gravity gives rise to buoyancy effects which tend to damp turbulence near the interface and cause thermal stratification, thus reducing the condensation rate. The reduction becomes significant as the Richardson number approaches unity."

A large velocity would yield a low Richardson number.

These authors summarized the previous work of Khoo, Sonin and Brown for high nozzle submergence $(z / D>3)$ as:

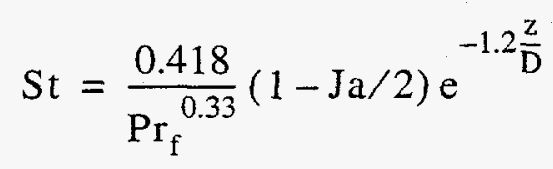

where

St $\quad=h_{i f} /\left(\rho_{f} C_{p f} Q / D d\right)$

At low jet submergence $(\mathrm{z} / \mathrm{D}<1.3)$ the form of the turbulence intensity prediction is changed from exponential to linear:

$$
\mathrm{v}_{\mathrm{b}}=\mathrm{v}_{\mathrm{j}}(\mathrm{d} / \mathrm{D})\left[10.4 \beta_{2^{-}}\left(7.14 \beta_{2^{-}}-3.06 \beta_{1}\right) \mathrm{z} / \mathrm{D}\right]
$$

a. Although the Brown-Helmick-Sonin paper has a publication date earlier than the Brown-Khoo-Sonin paper, the work was done later. 
where $\beta_{1}$ and $\beta_{2}$ are empirical coefficients which express the fact that the local turbulence is expected to be some fraction of the mean flow velocity.

$$
h_{i f}=\left(\frac{\mu_{f} C_{p f}}{D P P r_{f}^{0.33}}\right)\left(1-\frac{J a}{2}\right) \operatorname{Re}_{j}\left[0.2 \beta_{2}-\left(0.14 \beta_{2}-0.06 \beta_{1}\right) \frac{z}{D}\right]
$$

or in terms of Stanton number,

$$
\mathrm{St}=\left(1-\frac{\mathrm{Ja}}{2}\right)\left[0.2 \beta_{2}-\left(0.14 \beta_{2}-0.06 \beta_{1}\right) \frac{\mathrm{z}}{\mathrm{D}}\right] / \mathrm{Pr}_{\mathrm{f}}{ }^{0.33}
$$

Values of $\beta_{1}=0.34$ and $\beta_{2}=0.24$ allow Equation 14 to fit their data. Their data showed higher heat transfer rates than did Thomas's tests. $\beta_{1}=0.016$ and $\beta_{2}=0.20$ are needed to predict Thomas' data. They believe their data is more accurate than Thomas' data because, at large $\mathrm{z} / \mathrm{D}$ values, it appears to merge with the Brown, Khoo and Sonin data. Neither data set has error bars. Thomas states that heat losses were $10 \%$ as large as heat absorption in the water. Brown-Helmick-Sonin do not mention losses. Differences in the steam exit pipe design would make the Thomas data more susceptible to air built-up on the water.

To obtain data at lower water levels, they used the Brown, Khoo and Sonin large vessel $(\mathrm{D}=0.102 \mathrm{~m})$ at a pressure of $1.3 \mathrm{bar}$ and bulk Prandtl numbers between 2.3 and 5.1. A nozzle diameter which gave a D/d of 24 and one which gave a value of 64 were used. Data were obtained in the $0.5<z / D<3$ range. Table 4 summarizes the geometrical parameters.

Table 4 Brown, Helmick and Sonin Experiment Geometrical Parameters.

\begin{tabular}{|c|c|c|c|c|c|}
\hline $\begin{array}{c}\text { Vessel } \\
\text { Diameter } \\
\mathbf{D}(\mathbf{m})\end{array}$ & $\begin{array}{c}\text { Level } \\
\text { height } \\
\text { above } \\
\text { nozzle, } \mathbf{z} \\
(\mathbf{m})\end{array}$ & $\begin{array}{c}\text { Nozzle } \\
\text { Diameter } \\
\mathbf{d}(\mathbf{m})\end{array}$ & $\mathbf{z} / \mathbf{D}$ & $\mathbf{D} / \mathbf{d}$ & $\mathbf{z} / \mathbf{d}$ \\
\hline \hline 0.102 & $0.051-0.296$ & 0.00425 & $0.5-2.9$ & 24 & $12.0-69.7$ \\
\hline 0.102 & $0.112-0.255$ & 0.00159 & $1.1-2.5$ & 64 & $70.4-160.4$ \\
\hline
\end{tabular}




\subsection{Lin and Hasan Analysis (1990)}

Lin and Hasan ${ }^{9}$ performed a numerical analysis using a $\mathrm{K}-\varepsilon$ model of turbulence. They determined that the average value of the interfacial turbulent velocity is:

$$
v_{b}^{\prime}=v_{j}(2.39-0.645 z / D) d / D
$$

for jet Reynolds numbers between 10 and 60 thousand, $15<\mathrm{D} / \mathrm{d}<70$ and $0.5<\mathrm{z} / \mathrm{D}<2.5$. The Stanton number form shown in Equation $\mathbf{7}$ is used to obtain the final form:

$$
\mathrm{St}=\frac{0.0198}{\operatorname{Pr}^{0.33}}\left(1-\frac{\mathrm{Ja}}{2}\right)=\frac{\mathrm{h}_{\mathrm{if}}}{\rho_{\mathrm{f}} \mathrm{C}_{\mathrm{pf}} \mathrm{v}_{\mathrm{b}}^{\prime}} .
$$

\subsection{Brown's Thesis (1991)}

Brown's thesis ${ }^{\mathbf{1 0}}$ presents the same data as in the Brown-Helmick-Sonin paper. The 'raw' condensation data given in an appendix on page 133 are in terms of a dimensionless condensation parameter II:

$$
\mathrm{II}=\frac{\mathrm{Gh}_{\mathrm{fg}} \mathrm{DdPr}_{\mathrm{f}}^{0.33}}{\rho_{\mathrm{f}} \mathrm{C}_{\mathrm{pf}} \mathrm{Q} \Delta \mathrm{T}(1-0.5 \mathrm{Ja})}
$$

There appears to be a factor of 2 error when presenting the data in Figure 2.4 of the thesis and Figure 4 of the Brown-Helmick-Sonin paper. Dividing the correlation by 2 allows it to fit the data in the appendix and makes it unnecessary to have a smaller set of beta values to fit the Thomas data. From this point on predictions from the Brown-Helmick-Sonin correlation are divided by 2 .

\section{CORRELATION COMIPARISONS}

Figure 2 shows the liquid heat transfer coefficient versus $z / D$ for the two high and two medium water level correlations at a jet Reynolds number of 75000 . No data set spans the two regions. The data range marked Brown on the figure is data from Brown's thesis or the Brown-Helmick-Sonin paper. Data marked Khoo and Sonin is from the Brown-Khoo-Sonin and the Sonin-Shimko-Chun papers, respectively. 
Switching from Brown-Khoo-Sonin to Brown-Helmick-Sonin between a $z / D$ of 2.5 and 3.2 appears to be a reasonable albeit arbitrary way to program RELAP5.

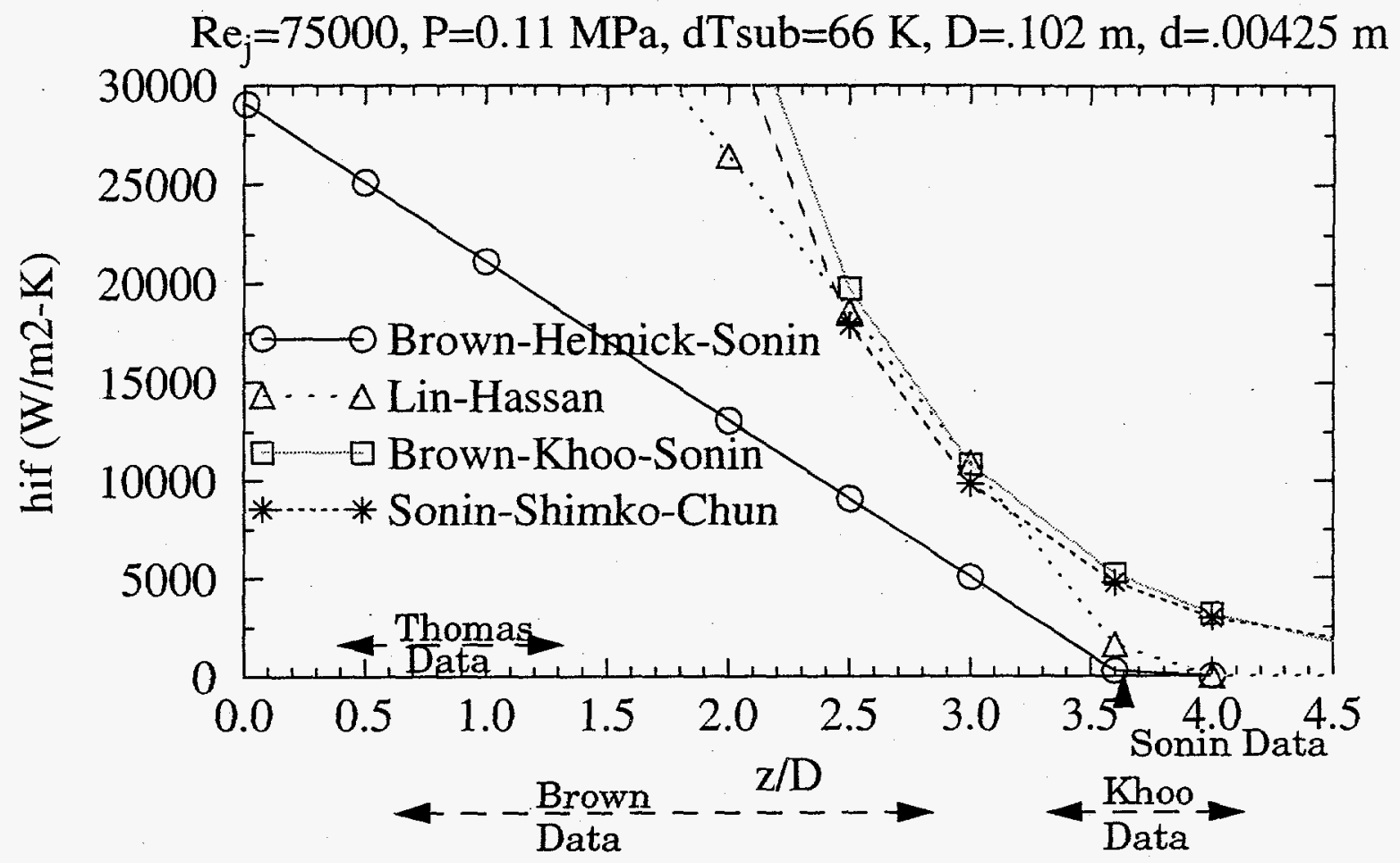

Figure 2. High and medium water level correlations.

Before presenting a comparison between the set of correlations chosen for RELAP5 and data, all the correlations will be compared together for two sample data sets. Correlation comparisons are presented for two sets of Thomas' data which have inlet velocities below the critical value. Figure 3 and Figure 4 compare the correlations at a $\mathrm{z} / \mathrm{D}$ value of 1.13 and 0.5 , respectively. The figures demonstrate the following:

1. Lin-Hasan predicts a heat transfer coefficient approximately twice the Brown-Helmick-Sonin value when the default values of beta are used in the Brown-Helmick-Sonin correlation with the 0.5 multiplier. The data splits these two correlations.

2. The Sonin-Shimko-Chun and Brown-Khoo-Sonin correlations do not predict the Thomas data since they were designed for higher water levels.

3. RELAP5 with only the McAdams natural convection coefficient will under-predict condensation rates. 


\section{Thomas}

Fig. $10 \mathrm{~b}, \mathrm{z} / \mathrm{D}=1.13, \mathrm{~d}=0.00635 \mathrm{~m}$

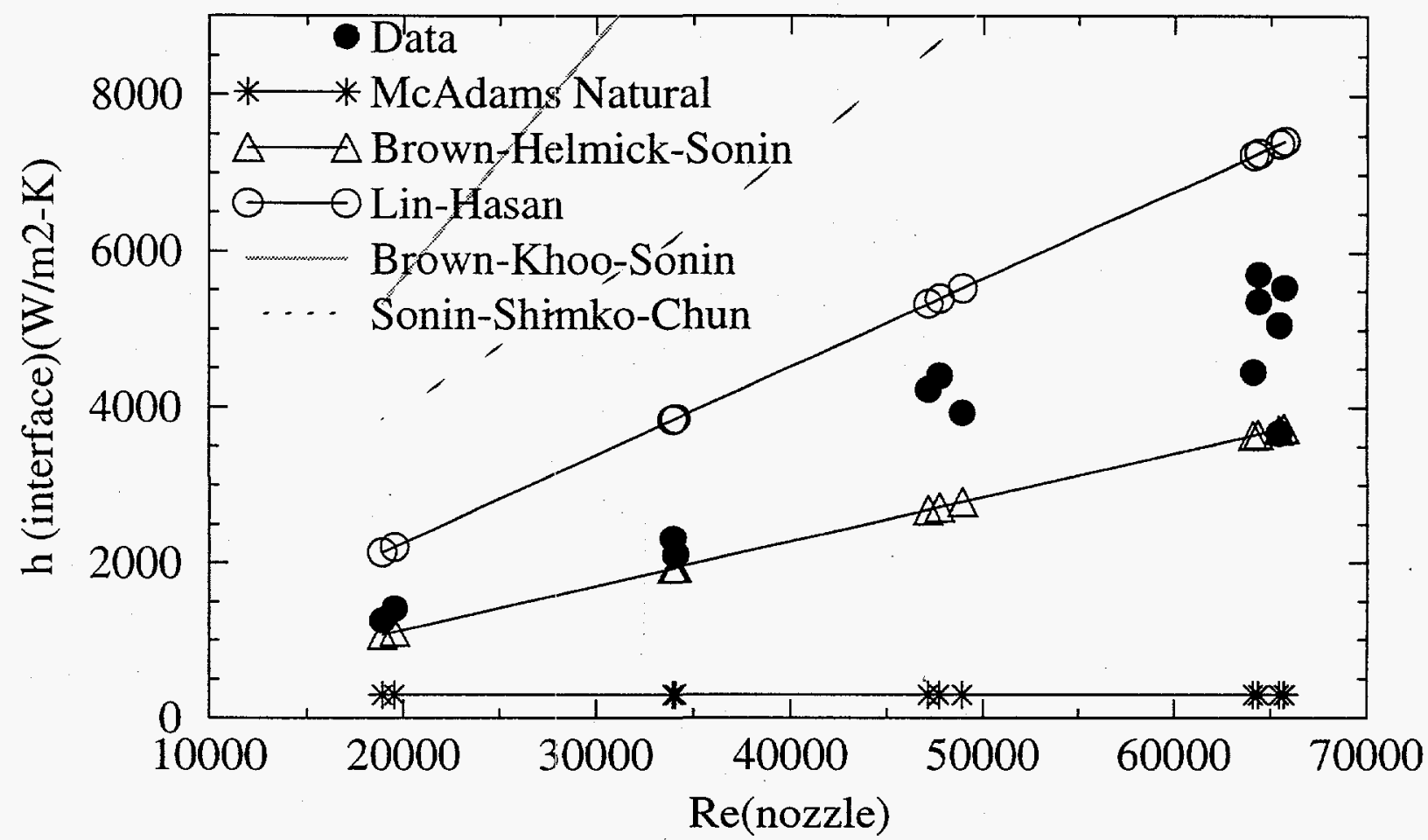

Figure 3. Correlation comparisons with Thomas' Figure 10b data.

\section{POST SURFACE BREAKUP MODEL}

Models which predict the condensation rate increase when a submerged jet breaks the surface were not found in the literature. This could be an interesting area for university research.

Thomas has given a method to predict the critical Kutateladze jet velocity at which breakup occurs for a given water level. One approach is to assume that the velocity head loss for 'no surface breakthrough' is predicted from the Kutateladze velocity, and any remaining kinetic energy causes a fountain as shown in Figure 1:

$$
\mathrm{v}_{\text {fountain }}^{2}=\mathrm{v}^{2}{ }_{\text {jet }}-\mathrm{v}^{2} \text { critical }
$$

where from Equation 3: 


\section{Thomas}

Fig. $10 \mathrm{e}, \mathrm{z} / \mathrm{D}=0.5, \mathrm{~d}=0.0127 \mathrm{~m}$

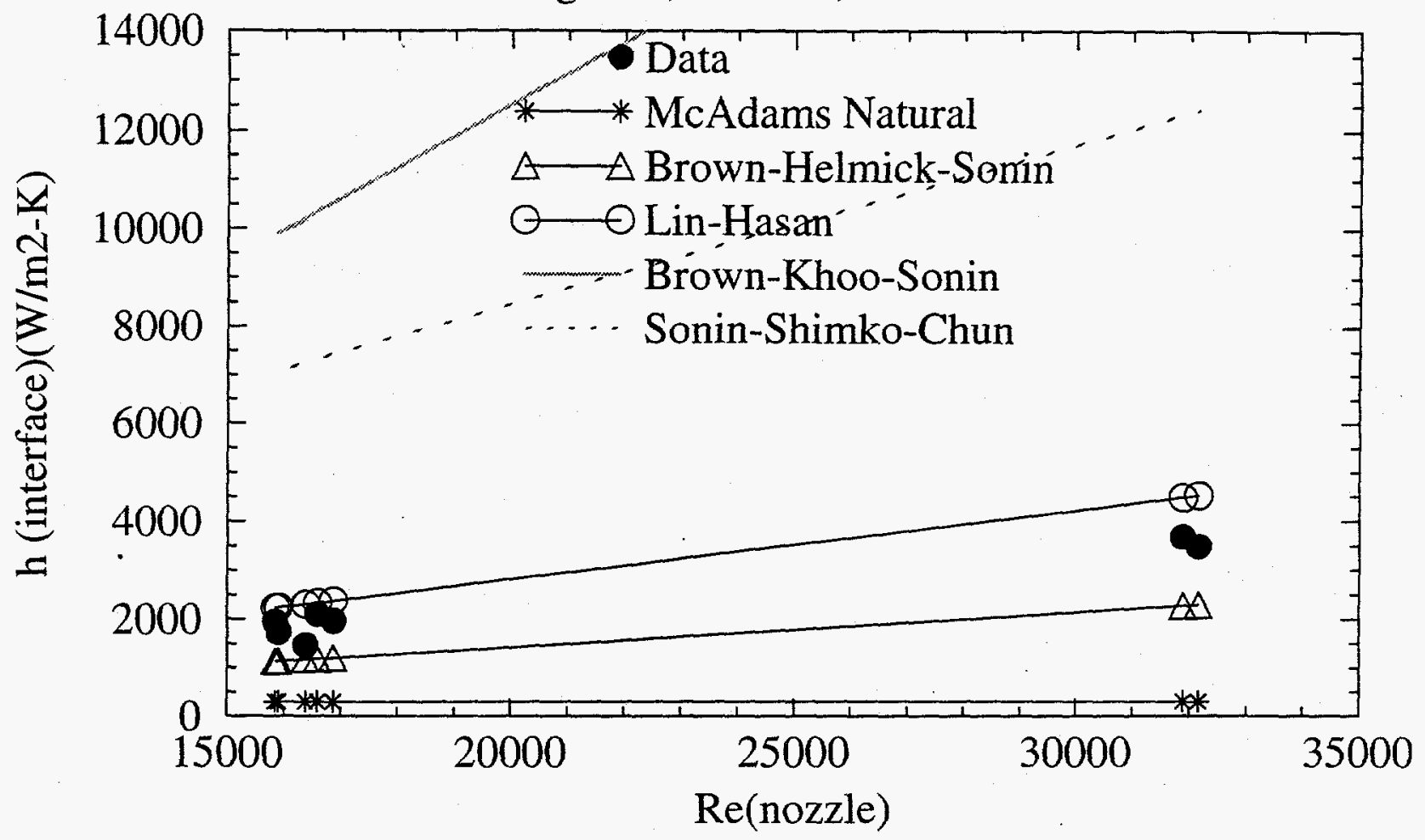

Figure 4. Correlation comparisons with Thomas' Figure 10e data.

$\mathrm{v}_{\text {critical }}^{2}=\left(0.46 \frac{\mathrm{z}}{\mathrm{d}}\right)^{2} \frac{(\Delta \rho \mathrm{g} \sigma)^{0.5}}{\rho_{\mathrm{f}}}$

The height of the water fountain above the surface $(\mathrm{H})$ is estimated using the Bernoulli equation which equates the initial kinetic energy to the potential energy at the top of the fountain:

$$
\mathrm{H}=\frac{\mathrm{v}_{\text {fountain }}^{2}}{2 \mathrm{~g}}
$$

The Theofanous' jet equation is invoked to predict the additional heat transfer. 


$$
\mathrm{St}_{\text {fountain }}=0.02\left(\frac{\mathrm{d}}{\mathrm{H}}\right)^{0.5}
$$

The fountain liquid-steam interfacial area and fountain diameter to use in Equation 22 is unknown. Until fountain heat transfer data is available, the jet diameter will be used fountain diameter. The interfacial area is approximated as twice the area of a cylinder of diameter $d$. The total heat transfer when the inlet velocity is larger than the critical velocity is the sum of the heat transfer to the fountain and the heat transfer to the stratified level. Two heat transfer areas are involved. The total energy rate is:

$$
\mathrm{q}_{\text {Total }}=\left(\mathrm{h}_{\text {iflevel }} \mathrm{A}_{\text {level }}+\mathrm{h}_{\text {iffountain }} \mathrm{A}_{\text {fountain }}\right)\left(\mathrm{T}_{\mathrm{s}}-\mathrm{T}_{\mathrm{b}}\right)
$$

$$
\mathrm{A}_{\text {level }}=\pi \mathrm{D}^{2} / 4
$$

$$
A_{\text {fountain }} \sim 2 \pi \mathrm{dH}
$$

$h_{\text {iflevel }}$ is from Brown-Helmick-Sonin or Brown-Khoo-Sonin and $h_{\text {iffountain }}$ is from the Theofanous jet correlation.

Thomas points out that some of the low water level data in his data set has an inlet velocity which exceeds the critical value. Assessments will be made by comparing total energy transfer to the liquid rather than with a total heat transfer coefficient.

Correlations such as Brown-Khoo-Sonin were developed to predict data without any fountain contribution. However, some of their data points have velocities which exceed the critical value. This indicates that the critical velocity correlation may not be accurate at high water levels. Consequently, the fountain contribution will be arbitrarily linearly ramped to zero between a $z / D$ of 0.5 and 1.0. Additional experiments need to be performed on the critical velocity in reactor geometries. 


\section{SUMMARY OF DATA AND RELAP5 MODEL}

Comparisons are made between the calculated energy exchange and the Thomas, Sonin-Shimko-Chun, Brown-Khoo-Sonin, and Brown-Helmick-Sonin data. Table 5 summarizes the test conditions.

Table 5 Data base parameters.

\begin{tabular}{|c|c|c|c|c|}
\hline Key Variables & $\begin{array}{c}\text { Thomas } \\
\mathbf{( 1 9 7 9 )}\end{array}$ & $\begin{array}{c}\text { Sonin- } \\
\text { Shimko- } \\
\text { Chun } \\
\mathbf{( 1 9 8 6 )}\end{array}$ & $\begin{array}{c}\text { Brown- } \\
\text { Khoo- } \\
\text { Sonin } \\
\mathbf{( 1 9 9 0 )}\end{array}$ & $\begin{array}{c}\text { Brown- } \\
\text { Helmick- } \\
\text { Sonin } \\
\mathbf{( 1 9 8 9 )}\end{array}$ \\
\hline \hline Pressure (MPa) & 0.11 & 0.11 & $0.11-0.31$ & 0.11 \\
\hline Subcooling (K) & 10 & $54-70$ & $17-98$ & $26-71$ \\
\hline Aspect Ratio (water level/diameter) (z/D) & $0.32-1.3$ & $3.1-4.2$ & 3.67 & $0.5-3.0$ \\
\hline Plenum/Pipe Diameter Ratio (D/d) & $24-94$ & 24 & 24 & 24,64 \\
\hline Jet Velocity (m/s) & $0.4-7.3$ & $3.7-18$ & $3-12$ & unknown \\
\hline
\end{tabular}

A summary of the method used to obtain the 'calculated' results in the following section is:

1. Use the critical Kutateladze velocity (Equation 20) to determine if the water level is high enough that only 'pre breakthrough' equations should be used.

2. For 'pre breakthrough':

Use Sonin-Shimko-Chun Equation 4 to calculate the turbulent velocity at the surface.

\section{Above $\mathrm{z} / \mathrm{D}=3.2$}

Use Brown-Khoo-Sonin Equation 7 to calculate the heat transfer.

Below $z / D=2.5$

Use Brown-Helmick-Sonin Equation 15 (multiplied by 0.5) with $\beta_{1}=0.34$ and $\beta_{2}=0.24$.

Between $z / \mathrm{D}=2.5$ and $z / \mathrm{D}=3.2$

Interpolate. 
3. For 'post breakthrough':

Calculate the surface heat transfer with the 'pre breakthrough' method.

Calculate the fountain heat transfer using the Theofanous equation. The fountain effect is ramped to zero between $\mathrm{z} / \mathrm{D}=0.5$ and $\mathrm{z} / \mathrm{D}=1.0$.

Add the 'pre breakthrough' results to the Theofanous results to get the total heat transfer rate.

\section{RELAP5 METHOD COMPARED TO DATA}

The above method has been implemented in a 'driver' program which uses the RELAP5 steam tables, and the results are shown below.

\subsection{Correlation Comparisons with Thomas' Data}

Thomas took data at six water levels. Data uncertainty was not given. The fluid temperature was also not given. The average value for all the tests was given and used in the prediction. The correlations used to predict the data were as described above with the 0.34 and 0.24 beta values in the Brown-Helmick-Sonin correlation plus the 0.5 multiplier. The data is rather scattered but the trends are predicted even above the critical velocity (see Figure 5). The three plots on the left hand side of the figure each have data taken at three nozzle sizes and the data on the right has two nozzle size data sets. The arrow on the figures shows the value of Kutateladze critical Reynolds number. To the right of the arrow the 'fountain or post breakthrough' model aids the data prediction. Solid lines represent the predictions. Multiple solid lines occur above the critical Reynolds number because of the inlet pipe diameters influence on the fountain velocity and height.

\subsection{Correlation Comparisons with Sonin-Shimko-Chun Data}

The correlation set chosen to be implemented into RELAP5 over-predicts the three Sonin-Shimko-Chun data sets as shown in Figure 6. The prediction is about $25 \%$ high for the middle data set. If the Sonin-Shimko-Chun correlation had been used instead of the Brown-Khoo-Sonin correlation the prediction would fit this data 
Thomas Fig. 10a, z/D=1.3

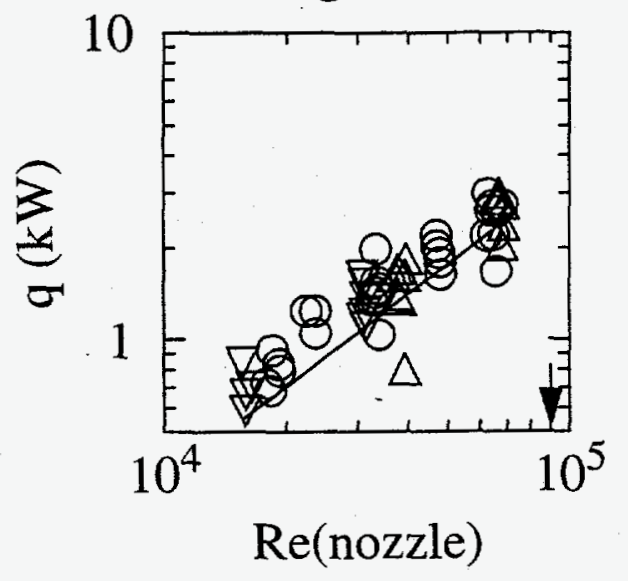

Thomas Fig. 10c, z/D=0.97

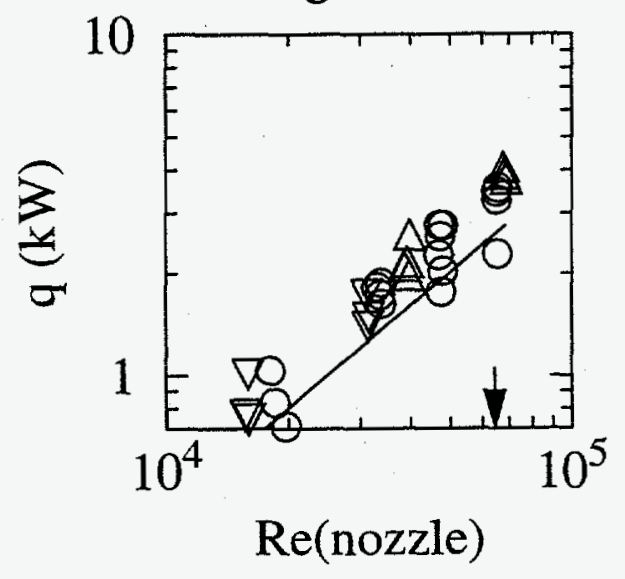

Thomas Fig. $10 \mathrm{e}, \mathrm{z} / \mathrm{D}=0.5$

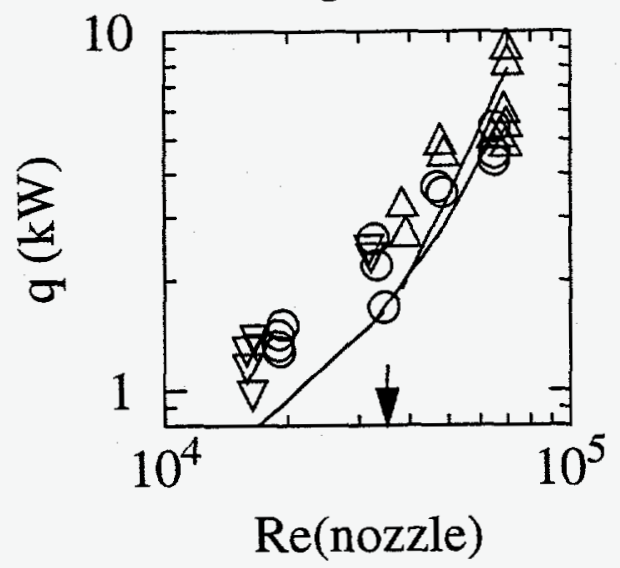

Data

$\nabla \mathrm{d}=12.7 \mathrm{~mm}$ $0 d=6.35 \mathrm{~mm}$ $\Delta \mathrm{d}=3.18 \mathrm{~mm}$
Thomas Fig. 10b, z/D=1.13

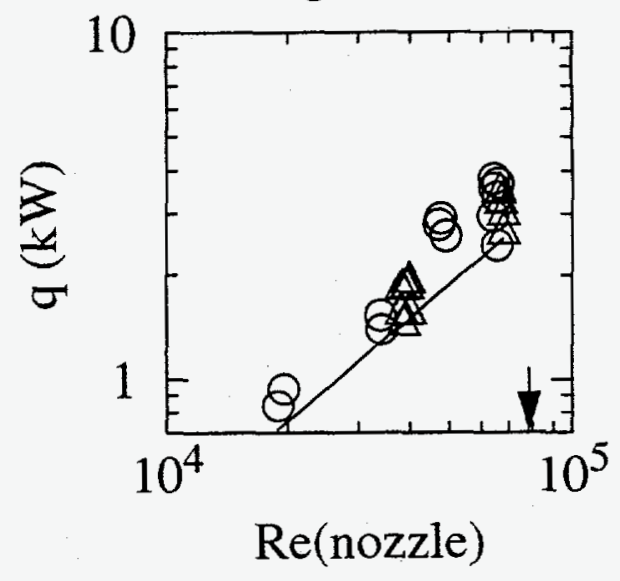

Thomas Fig. 10d, $z / \mathrm{D}=0.73$

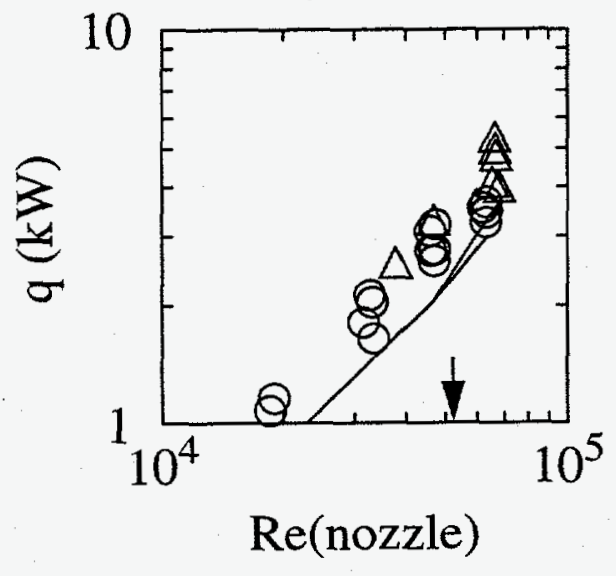

Thomas Fig. 10f, z/D $=0.32$

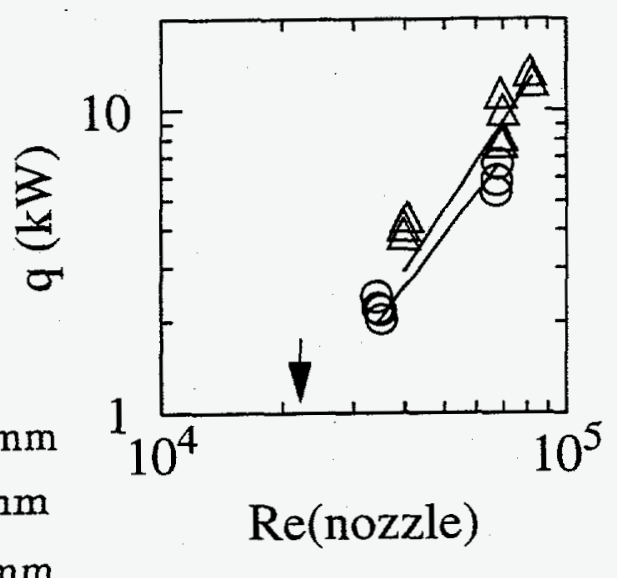

Figure 5. Thomas data and prediction (solid lines), arrows=critical Re. 
very well. However, the Sonin-Shimko-Chun correlation under-predicts some of the Brown-Khoo-Sonin data by $50 \%$.

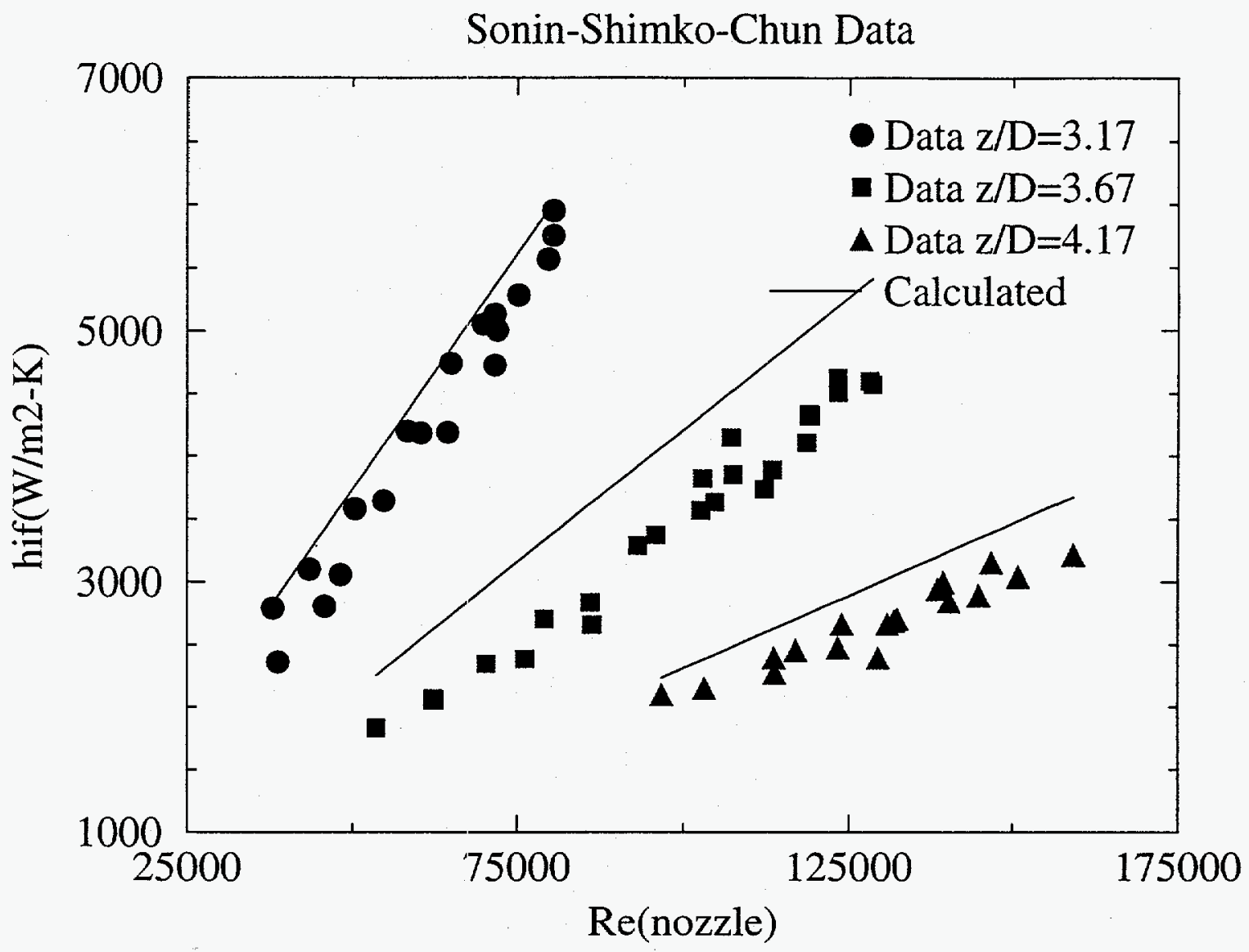

Figure 6. Sonin-Shimko-Chun data comparison with calculation.

\subsection{Correlation Comparisons with Brown-Khoo-Sonin Data}

Brown, Khoo and Sonin ran. tests at one water level, two pressures, nine values of water subcooling and two vessel/inlet pipe sizes. Both vessels had a D/d ratio of 24 . The $\mathrm{D} / \mathrm{d}$ dimensions of the big vessel and small vessel were $0.102 / 0.0042$ and $0.038 /$ 0.0016 , respectively. Table 6 shows the test conditions and the data symbols used in Figure 7. Large size symbols indicate data taken from the big vessel and small symbols indicate data from the small vessel.

Table 6 Brown-Khoo-Sonin test conditions; $\mathrm{z} / \mathrm{D}=3.67$.

\begin{tabular}{|c|c|c|c|}
\hline $\begin{array}{c}\text { Water } \\
\text { Temp (K) }\end{array}$ & $\begin{array}{c}\text { Prandtl } \\
\text { Number }\end{array}$ & $\begin{array}{c}\text { P=0.313MPa } \\
\text { (Tsat=408K) } \\
\text { symbol }\end{array}$ & $\begin{array}{c}\text { P=0.113MPa } \\
\text { (Tsat=376K) } \\
\text { symbol }\end{array}$ \\
\hline \hline 310 & 4.65 & $\bullet$ & $\bigcirc$ \\
\hline
\end{tabular}



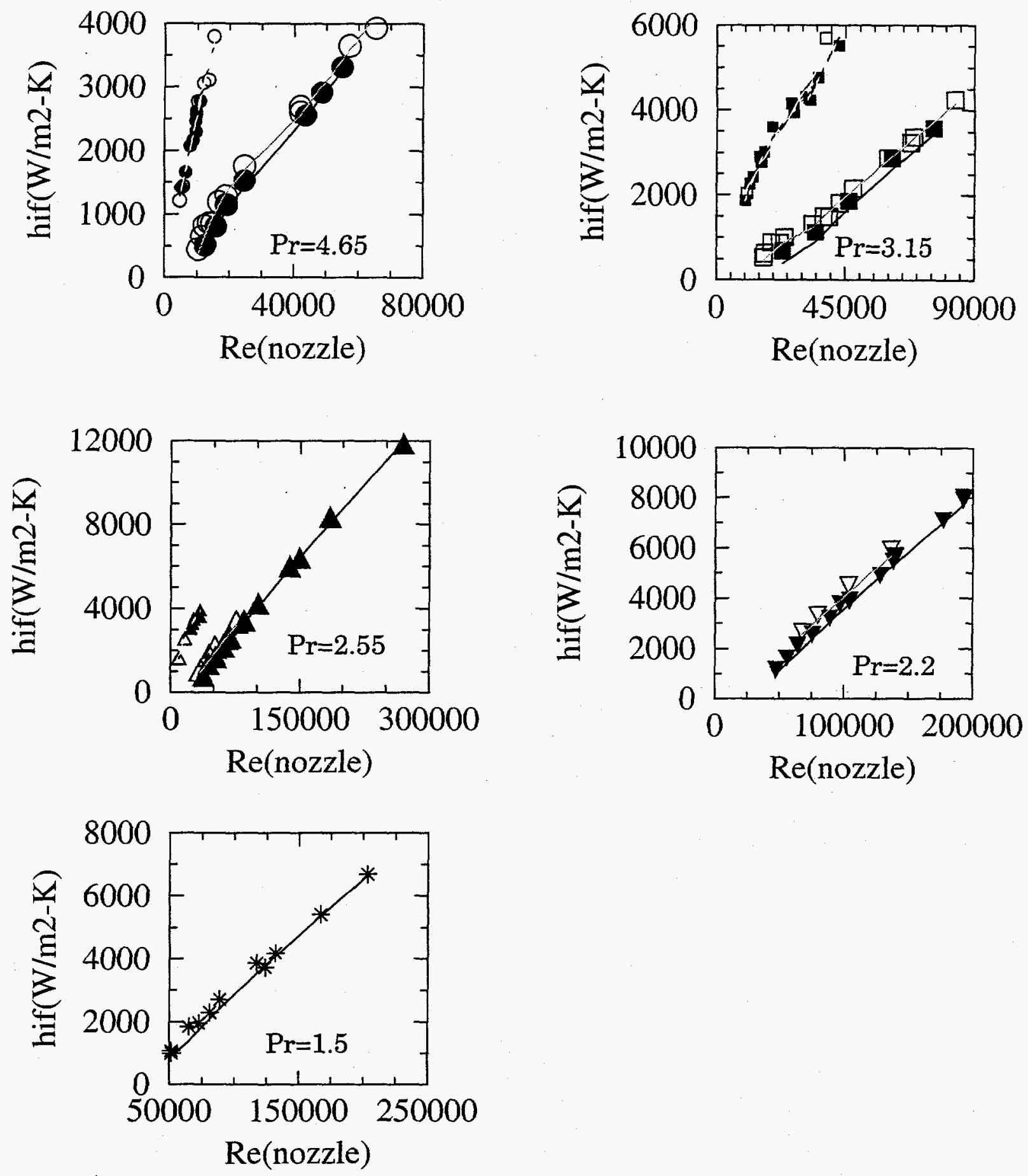

Figure 7. Brown-Khoo-Sonin data vs. calculation, $z / D=3.67$. 
Table 6 Brown-Khoo-Sonin test conditions; $z / D=3.67$. (Continued)

\begin{tabular}{|c|c|c|c|}
\hline $\begin{array}{c}\text { Water } \\
\text { Temp (K) }\end{array}$ & $\begin{array}{c}\text { Prandtl } \\
\text { Number }\end{array}$ & $\begin{array}{c}\text { P=0.313MPa } \\
\text { (Tsat=408K) } \\
\text { symbol }\end{array}$ & $\begin{array}{c}\text { P=0.113MPa } \\
\text { (Tsat=376K) } \\
\text { symbol }\end{array}$ \\
\hline \hline 330 & 3.15 & $\boldsymbol{\nabla}$ & $\square$ \\
\hline 344 & 2.55 & $\boldsymbol{\Delta}$ & $\Delta$ \\
\hline 355 & 2.2 & $\nabla$ & $\nabla$ \\
\hline 391 & 1.5 & $*$ & \\
\hline
\end{tabular}

As expected, the calculation matches the data well since the correlation used in the calculation was developed by Brown, Khoo and Sonin.

\subsection{Comparisons with Brown-Helmick-Sonin Data}

This data was taken by J. S. Brown ${ }^{10}$ as part of his MIT thesis work and covers $z / D$ values which overlap the Thomas data. However it does not overlap the SoninShimko-Chun data. Seventeen data points are reported in the thesis (two are identical). The data versus calculation values are shown in Figure 8. The error in the prediction of $h_{\mathrm{if}}$ is shown in Figure 9. The largest error is about $40 \%$. The mean error was about $-4 \%$ and the standard deviation was about $15 \%$.

\section{SUMMARY and CONCLUSIONS}

The RELAP5/MOD3 model for heat transfer on a stratified surface considered only natural convection. It therefore greatly under-predicts condensation on pool surfaces when a vertical jet causes turbulence. Adding models that predict the effects of jet induced turbulence results in improved predictive capability.

A model to predict surface breakthrough and heat transfer on an exposed liquid jet was added to RELAP5. This model yields adequate results when compared to the Thomas data. Additional data are desirable.

\section{References}

1. RELAP5/MOD3 Code Manual, NUCREG/CR-5553, INEL-95/0174, August 1995.

2. T. G. Theofanous, "Modelling of Basic Condensation Processes," Presented at the WRSE Workshop on Condensation, Silver Spring, Md. May 24-25, 1979. 


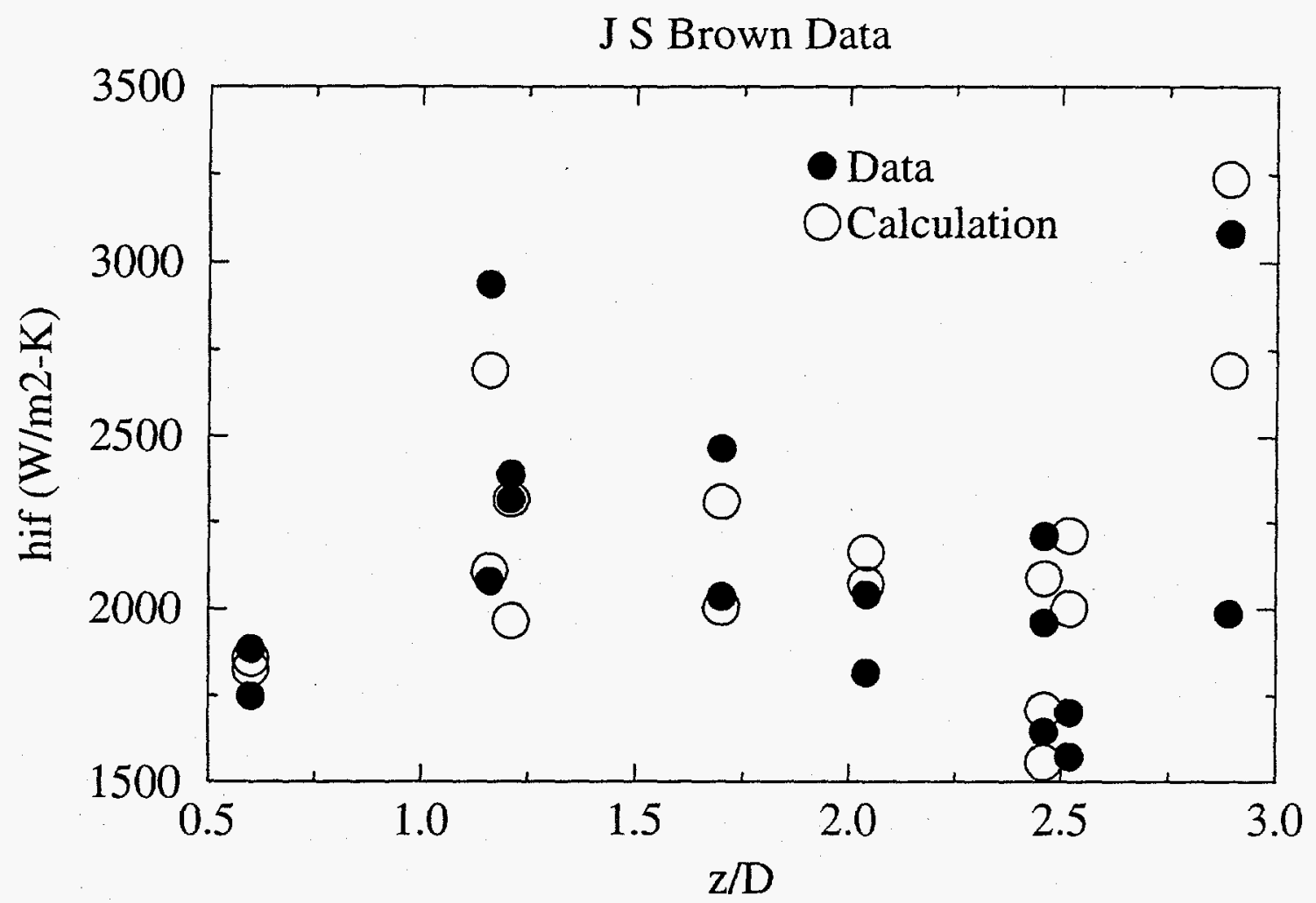

Figure 8. Comparison with Brown data in hif form.

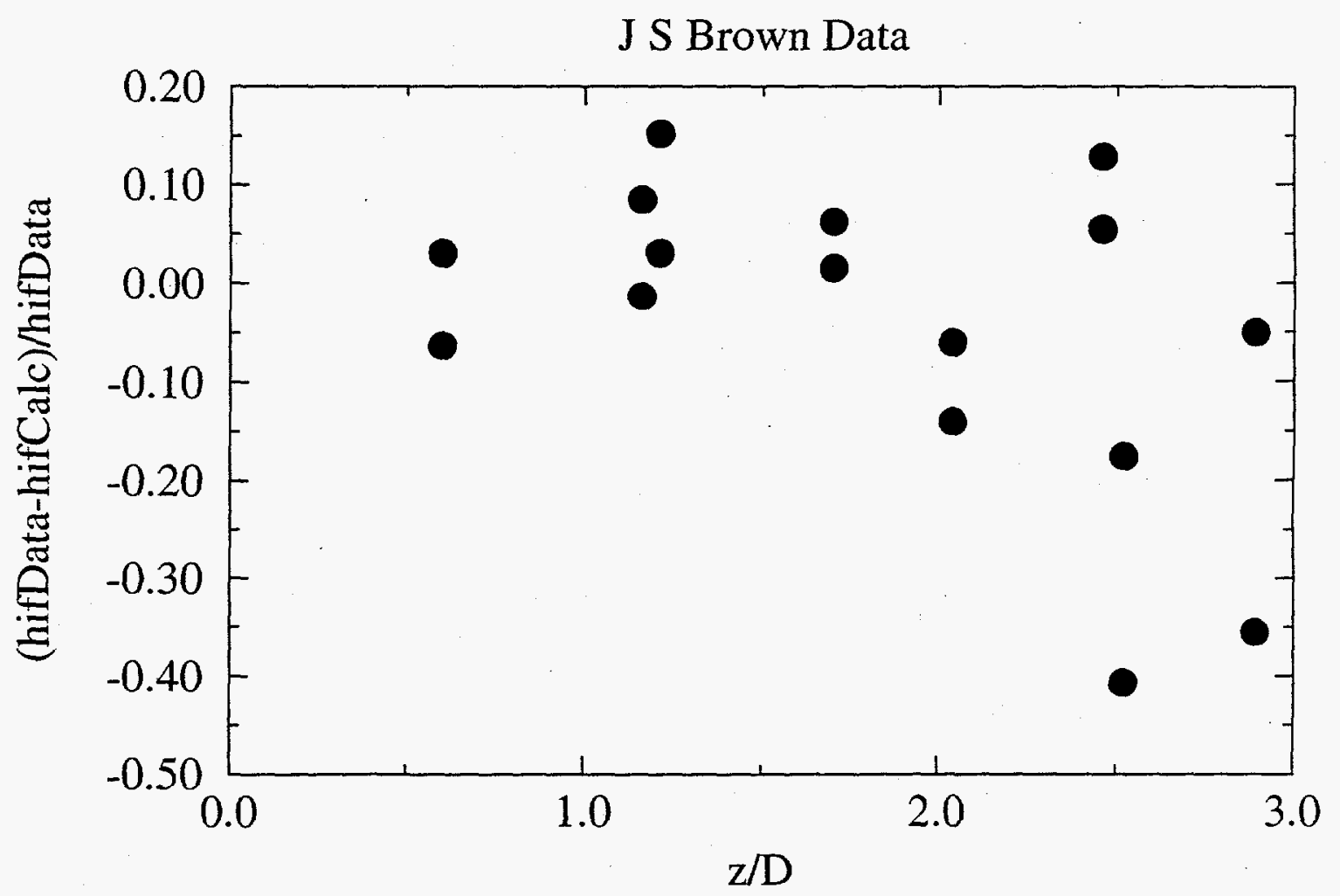

Figure 9. Brown data calculation error versus water level. 
3. R. M. Thomas, "Condensation of Steam on Water in Turbulent Motion," Int. J. Multiphase Flow, Vol. 5, pp. 1-15, 1979.

4. T. G. Theofanous, R. N. House and L. K. Brumfield, "Turbulent Mass Transfer at Free, Gas-Liquid Interfaces, with Applications to Open-Channel, Bubble and Jet Flows," Int. J. Heat and Mass Transfer, Vol. 19, pp. 613-624, 1976.

5. A. A. Sonin, M. A. Shimko, and J. Chun, "Vapor Condensation onto a Turbulent Liquid--I. The Steady Condensation Rate as a Function of Liquid-side Turbulence," Int. J. Heat and Mass Transfer, Vol. 29, No. 9, pp 1319-1332, 1986.

6. B. C. Khoo and A. A. Sonin, "Scalar Rate Correlation at a Turbulent Liquid Free Surface: A Two-Regime Correlation for High Schmidt Numbers," Int. J. Heat and Mass Transfer, Vol. 35, No. 9, pp 2233,2244, 1992.

7. J. S. Brown, M. R. Helmick, and A. A. Sonin, "Vapor Condensation at a Turbulent Liquid Surface in Systems with Possible Space-Based Applications," AIAA Paper 89-2846, July 1989.

8. J. S. Brown, B. C. Khoo, and A. A. Sonin, "Rate Correlation for Condensation of a Pure Vapor on Turbulent, Subcooled Liquid," Int. J. Heat and Mass Transfer, Vol. 33, No. 9, pp 2001-2018, 1990.

9. C. S. Lin and M. M. Hasan, "Effect of Liquid Surface Turbulent Motion on the Vapor Condensation in a Mixing Tank," NASA TM 105555, 1990. Also: Fourth International Symposium on Transport Phenomena in Heat and Mass Transfer, University of New South Wales, Sydney, Australia, July 14-19, 1991.

10. J. S. Brown, "Vapor Condensation on Turbulent Liquid," MIT, Ph.D. Thesis, May, 1991. 